\title{
La cultura i l'educació com a camins de resistència i d'alliberament: un estudi de cas
}

\section{Paula Escobar Muro*}

\section{Resum}

En aquest article presentem una recerca que té per objectiu explorar la cultura i l'educació com a eines de resistència i d'alliberament de les persones mitjançant la tècnica dels relats de vida. Al llarg del text desenvolupem una exploració teòrica del tema, una reflexió sobre el valor pedagògic dels relats de vida i un estudi de cas en què fem una anàlisi hermenèutica del relat de vida d'una persona. Els resultats obtinguts proposen que la cultura i l'educació són camins de resistència i d'alliberament de les persones en la mesura que fomenten la reflexió crítica i ens obren la porta a seguir preguntantnos com desenvolupar processos de transformació educativa que donin resposta a les problemàtiques socials contemporànies.

\section{Paraules clau}

Resistència, alliberament, reflexió crítica, transformació educativa, investigació biogràfica-narrativa, relats de vida.

\section{Introducció $^{1}$}

Demanem al lector o lectora que pensi en com se sent quan llegeix el seu llibre preferit, quan escolta una cançó gravada en els seus records i quan recorda un mestre o mestra que li va deixar petjada. Volem que es doni temps per notar amb calma les sensacions que es desperten quan evoca el llibre, la cançó i la persona. Tot i els matisos de la intimitat de cadascú, la majoria de les persones compartim aquestes vivències que ara estem introduint de manera orgànica i intuïtiva.

Aquest és el punt de partida de la recerca que presentem en aquest article: el sentiment que la cultura i l'educació ens connecten amb nosaltres mateixes, ens fan sentir més humanes i ens porten a aixecar fortalesa davant de les desventures de la nostra existència. En altres paraules, el tema de la recerca és la cultura i l'educació com a camins de resistència i d'alliberament de les persones.

L'hem representat amb la figura 1:

(*) Graduada en Pedagogia per la Universitat de Barcelona. L'autora s'interessa per la pedagogia crítica, la pedagogia llibertària, l'educació en valors i el valor educatiu de les arts i té experiència laboral com a professora de llengua anglesa d'infants, adolescents i adults. També és coeditora del llibre digital Pedagogías emergentes en la sociedad digital (vol. 2) i és tant autora com coautora de diversos escrits publicats en els espais virtuals Senderi i El Diari de l'Educació. Adreça electrònica: aluap19986@gmail.com

(1) Aquest article correspon al Treball de Fi de Grau que es va presentar en la convocatòria del mes de juny de 2020 i que va ser dirigit per Clara Domènech Vivas. 
Figura 1: La cultura i l'educació com a camins de resistència i d'alliberament de les persones.

(Elaboració pròpia, 2020)

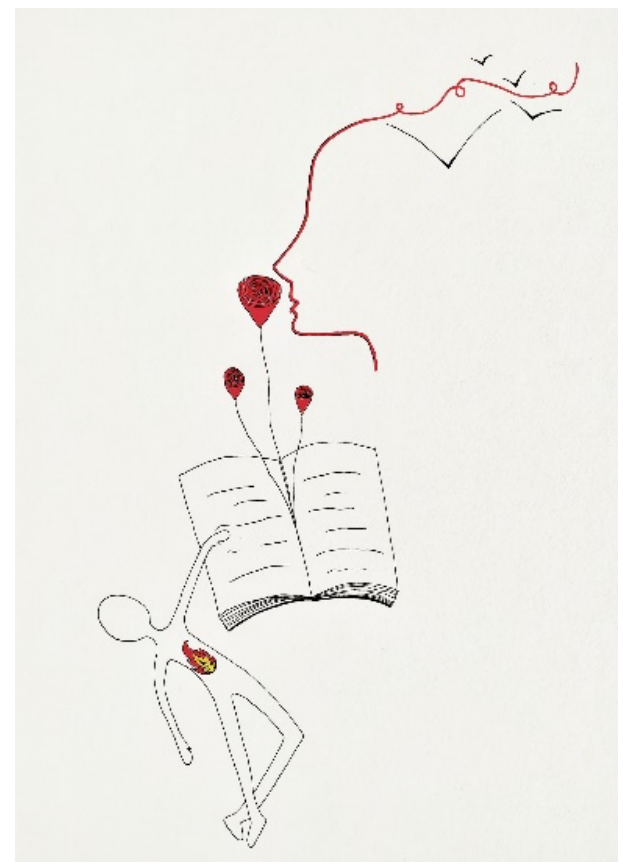

Mirem la il.lustració centrant l'atenció primer en el llibre. Aquest representa la cultura i l'educació i a ell es vinculen dues experiències: l'alliberament a dalt i la resistència a baix. L'alliberament es presenta mitjançant una silueta que, en olorar unes roses -les quals simbolitzen l'essència de la cultura i l'educació-, es transcendeix desprenent ocells que volen pel cel. La resistència apareix per mitjà d'una altra silueta que està a punt de caure al buit, però que s'aguanta gràcies al llibre. Aquesta té una flama al pit que està inspirada en les següents paraules de Josep Maria Esquirol (2015):

Tota resistència [...] és portadora, doncs, d'una esperança, de terme pretesament conegut o gairebé inexpressable. En qualsevol cas, s'és resistent i s'espera que la resistència no sigui en va, encara que el seu èxit no s'hagi de mesurar forçosament en els paràmetres usuals. Tal vegada la derrota serà o semblarà definitiva, tot $i$ això, el fet de mantenir viva la flama té sentit. (p. 15)

Aquesta és una manera visual de mostrar un tema que té el seu valor pedagògic en el fet que, a partir de la seva comprensió, els professionals de l'educació podem tenir criteri per tirar endavant processos de transformació educativa. El pensament pedagògic contemporani veu de fonts com l'Escola Nova i la pedagogia llibertària i, per tant, està compromès amb el desenvolupament integral de les persones, el respecte a la diversitat, la llibertat, l'equitat i la democràcia. A més, des de la pedagogia crítica es reivindica la necessitat de transformar el teixit social a través de l'educació per crear nous horitzons de justícia social. Aquest pensament exigeix una coherència de discursos i pràctiques que implica entendre els vincles que hi ha entre la cultura, l'educació, la resistència i l'alliberament si volem donar resposta a les problemàtiques socials contemporànies.

Orientant-nos en aquest sentit, l'objectiu de la recerca ha sigut explorar el tema fent una anàlisi hermenèutica del relat de vida d'una persona en relació amb els senders de resistència i d'alliberament que la cultura i l'educació han marcat en la seva vida. És a dir, hem navegat per les seves vivències per comprendre les sensacions que hem evocat a l'inici d'aquesta introducció. Els relats de vida són una tècnica de la investigació biogrà- 
fica-narrativa que permet atendre a la subjectivitat de les persones (Bolívar, 2002), democratitzar els discursos acadèmics (Bolívar, 2002; Ferrando, 2018) i empoderar els subjectes (Rueda, 2004). Exposarem aquestes qüestions extensament més endavant, però trobem convenient avançar que hem escollit utilitzar aquesta tècnica perquè la proximitat, la complexitat i la profunditat de la seva mirada ens permet endinsar-nos en un tema que està impregnat de sensacions, d'emocions i, citant a Antoine de Saint-Exupéry (2003), de l'essencial que és invisible als ulls. Concretament, hem recollit i analitzat el relat de vida d'una persona senzilla amb una història singular que pot aportar llum sobre el tema, ja que ha viscut dures experiències que han impactat fortament en la seva identitat alhora que ha trobat el seu refugi i la seva obertura al món en la cultura i l'educació. Per tal de garantir el dret a la intimitat i l'anonimat d'aquesta persona, l'anomenarem sota el pseudònim Antoni. Però abans de capbussar-nos en el cor de la recerca, farem un passeig teòric per aclarir què estem dient quan parlem de la cultura i l'educació com a camins de resistència i d'alliberament de les persones.

\section{La cultura i l'educació com a camins de resistència i d'alliberament}

Preguntar-nos sobre quina és l'essència de la cultura i de l'educació és el punt de partida necessari per comprendre el tema que ens pertoca. Si explorem en cerca de respostes, trobarem que els éssers humans som éssers inacabats, és a dir, que estem subjectes a la legalitat de la naturalesa però no ens esgotem en aquesta: som animals culturals oberts al món (Sánchez, 1996). La cultura és, doncs, un conjunt d'esquemes que donen perfils a un món que es presenta amorf i desordenat abans de la seva mediació (Larrosa, 2017) i l'educació és el procés en què les persones ens apropiem d'aquesta. Per tant, necessitem la cultura i l'educació per donar-li sentit al món i fer-lo habitable.

A més, fruit del nostre inacabament, les persones exercim la llibertat i hem d'assumir el nostre propi fer-nos des d'un aquí i un ara existencials (Sánchez, 1996). Aquest és el plantejament de Sartre de l'ésser humà com a projecte (Esquirol, 2015). Aquesta idea ens fa pensar que «el yo no es sino una continua creación, un perpetuo devenir: una permanente metamorfosis» (Larrosa, 2017, p. 50). També, el fet que l'ésser humà sigui un projecte porta implícita una condició històrica del jo; perquè hi hagi projecte, aquest ha d'estar unit al passat i en tensió cap al futur (Freire, 1979; Larrosa, 2017; Sánchez, 1996). Si som éssers històrics en canvi constant, vol dir que tenim memòria i imaginació: la memòria ens porta a recordar el passat per comprendre el present i la imaginació ens permet visualitzar noves realitats per crear-les en la nostra acció. Tenint en compte aquests fets, Larrosa (2017) planteja que la nostra identitat té una forma narrativa i que les persones ens donem sentit i ens fem a través de les paraules. En un món emparaulat només és possible aprendre a través del diàleg (Vilanou, 2002). Per tant, I'educació és un diàleg amb la cultura, les persones i el món en què construïm la nostra identitat.

Si assumim que les persones som projectes inacabats que donem forma al món i a nosaltres mateixes a través de la cultura i l'educació, ens toparem aviat amb el concepte Bildung. Aquest es tradueix com a formació -tot i que en altres moments també s'ha associat amb cultura- i és una idea que travessa la pedagogia contemporània en plantejar que els éssers humans no som per naturalesa el que hem de ser i, per tant, necessitem formar-nos a través de la cultura perquè el nostre esperit progressi i s'elevi a la seva condició humana, en la qual preval la llibertat, la totalitat, la creació i la plenitud vital (Vilanou, 2002). Ara bé, què és ser plenament humà? Davant d'aquesta pregunta, Jorge Larrosa (2017) afirma que en la literatura posterior a Goethe hi ha hagut un esquinçament en la 
idea tradicional de Bildung -pel fet que l'ésser no pot trobar el valor i el sentit de la seva existència- i va més enllà d'ella en defensar una formació que no porti cap a una idea preescrita de què és ser humà, sinó que sigui un viatge obert en què les persones ens fem, desfem i refem constantment sent portades progressivament a la nostra forma pròpia, la qual és singular en cadascuna.

En aquest marc, la cultura i l'educació esdevenen espais de possibilitat des d'on les persones podem comprendre i transformar tant el món com a nosaltres mateixes. Freire (1979) defineix el diàleg educatiu com la trobada de les persones per pronunciar el món, com una exigència existencial per comprendre'l i com un acte creador per transformarlo. Aquests dos elements, comprensió i transformació, no es poden entendre per separat, sinó que són una mateixa unitat. Les persones transformem la realitat i alhora aquesta ens condiciona, pel que estem en constant interacció entre reflexió i acció: som éssers de praxi (Freire, 1979). Gràcies a aquest potencial per mobilitzar processos comprensius i transformadors, la cultura i l'educació poden ser senders de resistència i d'alliberament de les persones.

Aprofundim, doncs, en què són la resistència i l'alliberament des d'una mirada pedagògica i quins vincles tenen amb la cultura i l'educació. Per definir la resistència ens basem en el concepte d'aquesta que estableix el filòsof Josep Maria Esquirol. Val a dir que Esquirol (2015) parteix de què els éssers humans portem el no-res a dins. Aquest és, sobretot, una experiència en què ens angoixem perquè no trobem sentit a la nostra existència ni al nostre esdevenir. Vivim, per tant, en un procés de nihilització en què el no-res ens va consumint de mica en mica. A més, aquest procés s'intensifica en determinades circumstàncies que, per la seva duresa, són forces disgregants del nostre ésser. Davant d'aquests fets, Esquirol (2015) proposa que existir és resistir, entenent la resistència com un moviment de l'existència humana caracteritzat per la fortalesa que aixequem davant dels processos de desintegració i corrosió que vénen de l'entorn i de nosaltres mateixos. Aquesta resistència té un caràcter íntim, ja que es configura en l'empara que el recolliment, la proximitat i la cura ofereixen davant de la disgregació de l'ésser i la duresa de les condicions exteriors (Esquirol, 2015). En resposta a les imatges del buit, l'abisme i la foscor, trobem les de la casa, la mà amiga i la quotidianitat. Per això, la resistència no s'ha de confondre amb la protesta cridanera, sinó que més aviat acostuma a ser discreta (Esquirol, 2015; Giroux, 1985).

El vincle entre la resistència i la cultura es troba en el fet que «la cultura es, sin embargo, tanto el sujeto como el objeto de la resistencia» (Giroux, 1985, p. 37). Des d'una perspectiva crítica, les teories de la reproducció i la resistència proposen que les escoles són instruments de reproducció social i cultural, els mecanismes de les quals es troben amb elements d'oposició i, per tant, de resistència (Giroux, 1985). Si estenem aquest mateix fenomen a l'educació no formal i informal, és versemblant afirmar que l'apropiació de la cultura a través de l'educació pot generar processos de reproducció social i cultural que afavoreixen la disgregació de l'ésser en perpetuar dures condicions per les persones, com ara les desigualtats i la violència. Tanmateix, són també la cultura i l'educació les que generen processos de resistència perquè, tal com hem introduït anteriorment, permeten que les persones comprenem i transformem aquestes mateixes condicions. L'essència de la cultura i l'educació com a camins de resistència es pot resumir en el fet que, gràcies al seu potencial comprensiu i transformador, aquestes poden ser una font de sentit i de canvi davant del procés de nihilització. 
La resistència íntima és, doncs, condició de possibilitat de l'ésser humà com a projecte, ja que és un refugi des del qual observar el món i orientar-se en aquest (Esquirol, 2015). Per tant, també és condició de possibilitat de l'alliberament, el qual podem definir com el moviment dels éssers humans de cerca constant de ser més, és a dir, d'humanitzar-nos i transcendir-nos (Freire, 1979). Establim aquesta analogia perquè podem observar que en la definició de l'expressió ser més descansa la idea que l'ésser humà és un projecte que necessita elevar-se a la seva condició humana. A més, Freire (1979) proposa que l'alliberament no es diposita en les persones, sinó que és praxi, això és, reflexió i acció per transformar(-nos). Però, té aquesta cerca de ser més un horitzó final? Davant d'aquesta pregunta, Freire (1979) diu que l'alliberament és un procés permanent. Si recordem que no avancem cap a una idea pre-escrita de què és ser humà, sinó que vivim un viatge obert en què canviem constantment, no és coherent pensar en un horitzó final. Per això, Larrosa (2017) defensa que les persones ens fem de desfer-nos, ens diem de desdir-nos i ens alliberem quan ens qüestionem a nosaltres mateixes.

Els vincles entre la cultura, l'educació i l'alliberament s'evidencien quan assumim, tal com hem desenvolupat fins ara, que alliberar-se és humanitzar-se i que ens humanitzem quan ens formem. Per explicar aquesta relació tornem de nou al fet que la cultura i l'educació ens permeten comprendre i transformar i, per tant, a través d'elles podem buidar el nostre jo per llegir i actuar sobre el món amb una mirada renovada. Larrosa (2017) expressa aquesta qüestió:

Hay que hacer continuamente que esas palabras desgarren y hagan estallar las palabras preexistentes. Sólo el combate de las palabras aún no dichas contra las palabras ya dichas permite la ruptura del horizonte dado, permite que el sujeto se invente de otro modo, que el yo sea otro. (p. 50-51)

Freire (1979) també afirma que aquesta cerca de ser més no pot realitzar-se en l'individualisme, sinó que es dona en la comunió i la solidaritat de les persones, en el nostre diàleg per pronunciar el món o, en altres paraules, en l'acció cultural i educativa. Seguint aquesta línia de pensament, bell hooks ${ }^{2}$ (1994) descriu l'essència de la cultura i l'educació com a camins d'alliberament de les persones:

Learning is a place where paradise can be created. [...] With all its limitations, remains a location of possibility. In that field of possibility we have the opportunity to labor for freedom, to demand of ourselves and our comrades, an openness of mind and heart that allows us to face reality even as we collectively imagine ways to move beyond boundaries, to transgress. This is education as the practice of freedom. (p. 207)

Malgrat això, la cultura i l'educació no són alliberadores sempre. Igual que aquestes poden ser tant l'objecte com el subjecte de la resistència, també tenen la possibilitat tant d'oprimir-nos com d'alliberar-nos (Freire, 1979). Això ocorre perquè el diàleg de les persones amb el món pot tant humanitzar-nos com deshumanitzar-nos a causa de la nostra naturalesa problemàtica (Freire, 1990). Davant d'aquestes ambivalències, la cultura i l'educació poden ser vies de resistència i d'alliberament les persones si el seu sentit s'orienta en aquesta direcció (hooks, 1994). Per fer-ho, Freire (1979) proposa que aquestes han de promoure la reflexió crítica, la qual suposa l'emersió de les consciències de les persones i la seva inserció crítica en la realitat.

Anem una mica més enllà en què és la reflexió crítica i quins són els seus vincles amb la cultura, l'educació, la resistència i l'alliberament. El primer pas és introduir el fet que els

(2) bell hooks s'escriu en minúscula i és el pseudònim de l'escriptora, catedràtica i activista social feminista Gloria Jean Watkins. 
éssers humans tenim consciència; en altres paraules, som éssers que sabem que no només existim en el món sinó amb el món i, per tant, que podem comprendre la realitat i transformar-la en la nostra acció. Aquesta consciència es va desenvolupant durant la conscienciació, la qual Freire (1990) defineix com «el proceso mediante el cual los hombres, no como receptores, sino como sujetos de conocimiento, alcanzan una conciencia creciente tanto de la realidad sociocultural que da forma a sus vidas, como de su capacidad para transformar dicha realidad» (p. 85). En aquest procés, les persones avancem progressivament d'un nivell de consciència dependent a un nivell de consciència crítica, en el qual podem qüestionar la realitat i la nostra identitat per generar canvis en aquestes a través d'accions com produir, decidir, crear i comunicar-nos (Freire, 1990). En aquest nivell apareix la reflexió crítica, la qual es vincula amb la resistència i l'alliberament de les persones perquè ens convida a pensar-nos sense atenir-nos als projectes que els altres tenen de nosaltres, a no conformar-nos, a preguntar-nos el perquè dels fets, a visualitzar nous horitzons personals i comunitaris i a actuar amb criteri per realitzar-los.

De nou, la cultura i l'educació són el medi necessari per cultivar la reflexió crítica perquè ens permeten comprendre i transformar. Larrosa (2017) presenta aquest vincle quan, en comentar dos textos de Peter Handke, afirma que en aquests «el viaje [formatiu] se plantea como la búsqueda de una nueva forma de experiencia del mundo y de uno mismo, como el intento de alcanzar un nuevo umbral de conciencia» (p. 67). En resum, la cultura i l'educació són senders de resistència i d'alliberament de les persones en la mesura que promouen la reflexió crítica.

\section{Metodologia}

En aquest article presentem una investigació qualitativa i biogràfica-narrativa en què s'ha fet ús de la tècnica del relat de vida. Anem pas a pas. Les investigacions qualitatives són aquelles que busquen comprendre els objectes d'estudi en la seva situació natural (Denzin i Lincoln, 1994), centrant-se a descobrir el sentit, la lògica i la dinàmica de les accions humanes concretes i reivindicant el que és subjectiu, intersubjectiu, significatiu i particular (Rueda, 2004). Dins d'aquest tipus d'investigació, l'enfocament biogràfic-narratiu es basa a reconstruir la vida, completament o parcialment, dels éssers humans per tal de comprendre els subjectes a partir de la seva experiència vital (Saltalamacchia, 1987). Entre les tècniques d'investigació que se situen en aquest enfocament, és necessari que en diferenciem dues que sovint es confonen conceptualment: la història de vida i el relat de vida. No és el mateix la història viscuda per una persona que el relat que ella fa d'aquesta història a petició d'un investigador en un moment determinat (Bertaux, 2005). Per això, Norman K. Denzin (citat a Ascanio, 1995 i a Martín, 1995) va establir una distinció entre el relat de vida (life story) i la història de vida (life history): el primer és la narració que una persona fa de la seva vida en el context d'una entrevista amb un investigador o investigadora, mentre que la segona comprèn el relat de vida més entrevistes a persones del seu entorn social i altres documents que el completen. Conscients d'aquesta diferència, com el nostre interès es trobava en la narració personal de l'experiència de l'Antoni, vam decidir fer ús de la tècnica del relat de vida. Però abans d'endinsar-nos en el plantejament de la recerca, volem fer una breu pausa per desenvolupar les potencialitats i les limitacions dels relats de vida en l'àmbit de la pedagogia per tal de destacar la rellevància d'aquesta tècnica d'investigació. 


\section{Potencialitats i limitacions dels relats de vida en l'àmbit de la pedagogia}

La pedagogia actual es troba immersa en una època postmoderna en què s'ha viscut un desengany respecte a les grans narratives educatives. Segons Daura Fried Schnitman (citada a Rueda, 2004):

Assistim a la dissolució dels discursos homogeneïtzants i totalitzants en la ciència i la cultura. No existeix narració o gènere del discurs capaç de donar un traçat únic, un horitzó de sentit unitari de l'experiència de la vida, la cultura, la ciència o la subjectivitat. Hi ha històries en plural. (p. 58)

En aquest marc, I'hermenèutica ha adquirit un gran pes com a mode de coneixement enfront del progressiu esgotament del positivisme (Bolívar, 2002). Dins d'aquest gir hermenèutic, la principal característica dels relats de vida, igual que la de les altres tècniques d'investigació biogràfica-narrativa, és la subjectivitat que emergeix d'ells, la qual és alhora el punt de partida de les seves potencialitats i limitacions (Rueda, 2004).

Comencem per les potencialitats. La primera la trobem en el fet que la investigació biogràfica-narrativa recull qüestions que acostumen a quedar excloses de la investigació formal: els sentiments, les sensacions, els propòsits, les pors... L'univers íntim de la persona que narra (Bolívar, 2002). Atendre a aquest univers subjectiu permet comprendre l'experiència humana en la seva complexitat i profunditat (Bolívar, 2002) per construir un saber pedagògic pròxim que doni resposta als problemes, les necessitats i els desitjos reals de les persones. D'aquesta capacitat per desvelar l'ocult parteix una segona potencialitat: el caràcter oral i narratiu dels relats de vida permet democratitzar i fer crítics els discursos acadèmics, ja que l'ús de fonts orals dona accés a què persones allunyades dels centres de poder comparteixin la seva experiència vital (Bolívar, 2002; Ferrando, 2018). Els relats de vida s'obren a la pluralitat de veus de les persones senzilles i silenciades per tal de construir una educació que aculli la gran diversitat de persones que l'habiten. Una tercera potencialitat és que narrar l'experiència personal constitueix un acte empoderador perquè permet que les persones posin paraules a qüestions que normalment resten sense anomenar, donin valor a la seva pròpia veu i prenguin consciència de les seves vivències per generar transformacions educatives. Rocío Rueda (2004) expressa aquesta idea quan escriu sobre el mètode biogràfic que es va aplicar en una investigació sobre la vida dels mestres colombians:

Des d'aquesta perspectiva, investigar no és solament conèixer, també és fer en el sentit de les possibilitats que obre el procés reflexiu que tant investigadors com mestres realitzen, per repensar el passat, el present i el futur, per ser conscients dels seus vincles i imaginar-se, i efectivament crear, societats possibles. (p. 58)

Aquesta orientació cap a la creació a partir de la reflexió sobre l'experiència suposa un canvi de mirada que trenca amb les grans narratives educatives i s'abraça a la proximitat i a la quotidianitat de la vida humana, que és des d'on és possible fer canvis educatius valuosos per les persones.

Per un altre costat, trobem les limitacions. La primera és que els subjectes relaten les seves vivències interpretant-les des de la distància del temps, pel que no s'assegura una cristal-lina fidelitat a aquestes (Rueda, 2004). Tanmateix, la investigació biogràfica-narrativa no busca la veritat en termes absoluts, sinó la veracitat en el coneixement sobre com donem significat a l'experiència quotidiana. Són aquests subjectes amb una història vital acumulada els únics capaços de reconstruir el passat i revisar-lo des del present per dotar de sentit allò que narren (Rueda, 2004). Una segona limitació la trobem en el fet que és complex generalitzar els resultats obtinguts a través dels relats de vida (Bertaux, 2005) perquè les persones tenim experiències educatives molt diferents i les vivim de maneres 
ben distintes. Davant d'aquest fet hem de tenir en compte que participant en una cultura particular s'adquireixen formes de comprendre, metàfores, paràmetres, eines cognitives i destreses, pel que en recollir les històries individuals es recupera també l'imaginari social (Rueda, 2004). Aquesta limitació es pot abordar, doncs, multiplicant la quantitat de relats de vida analitzats en una investigació educativa per tal d'obtenir experiències molt diverses que puguin ser comparades entre elles i, així, descobrir el que és general entre les formes particulars (Bertaux, 2005). Aquesta qüestió ens porta a una tercera limitació: la quantitat de relats de vida que es poden recollir i analitzar és limitada perquè la tasca exigeix una dedicació exhaustiva tant de temps com d'esforços. Així i tot, aquesta exhaustivitat li dóna a la investigació biogràfica-narrativa el seu valor i ens recorda que la seva aspiració no és construir visions de conjunt ni models explicatius generals, sinó atendre a la subjectivitat de les persones buscant els trets comuns i valorant les diferències entre elles (Susinos i Parrilla, 2008).

\section{Plantejament de la recerca}

En la recerca que presentem en aquest article vam estudiar el cas de l'Antoni per tal d'analitzar els camins de resistència i d'alliberament que la cultura i l'educació han establert en la seva vida. Primer vam recollir el seu relat de vida a través de realitzar i enregistrar onze entrevistes semiestructurades amb ell en què vam resseguir tota la seva trajectòria vital. En cada una d'elles vam tractar un o dos blocs de la seva vida focalitzant-nos en el tema del nostre interès, els quals havíem definit seguint un ordre cronològic i temàtic en una reunió inicial amb ell. Després vam transcriure el total d'onze hores de gravacions que van resultar, vam crear una línia de vida de l'Antoni i vam fer una anàlisi hermenèutica del relat de vida obtingut. Per portar a terme aquesta anàlisi vam dividir el tema general en tres blocs temàtics i cada un d'aquests els vam subdividir en diverses categories d'anàlisi d'acord amb les que vam identificar en l'exploració teòrica del tema:

Taula 1. Organització dels blocs temàtics i de les categories d'anàlisi

Bloc temàtic

Categories

1. La cultura i l'educació com a eines de resistència de les persones

1.1. Experiència del no-res i disgregació de l'ésser

1.2. Resistència a la reproducció

1.3. Resistència íntima

2. La cultura i l'educació com a eines d'alliberament de les persones

2.1. Formació com a ser més

2.2. Trobada amb l'altre

3. La cultura i l'educació com a eines d'alli-

3.1. Comprensió, reflexió i memòria

berament i de resistència de les perso-

3.2. Transformació, acció i imaginació nes

3.3. Reflexió crítica

Font: Elaboració pròpia, 2020

Tot seguit, vam vincular a cada categoria diversos fragments del relat de vida de l'Antoni i vam establir un diàleg entre ell i els autors referenciats a l'exploració teòrica del tema respecte a l'element tractat en la categoria corresponent. Passem, doncs, a conèixer els resultats obtinguts. 


\section{Resultats}

Vam crear la línia de vida de l'Antoni a partir del relat obtingut:

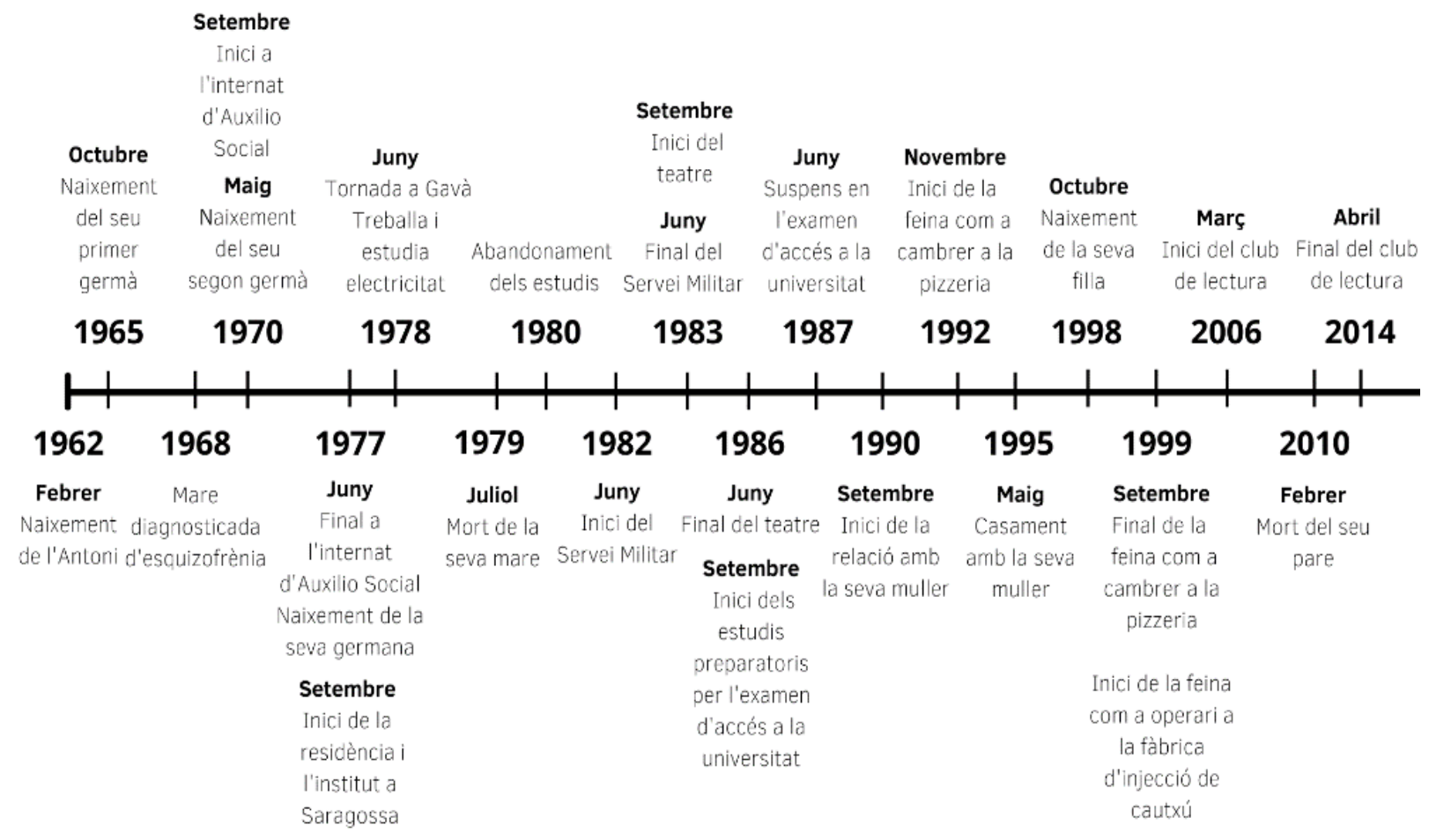

Figura 2. Línia de vidade l'Antoni. (Elaboració pròpia, 2020)

Considerant aquesta trajectòria vital, seguidament presentem l'anàlisi hermenèutica del relat de vida de l'Antoni dividida en els blocs temàtics i les categories d'anàlisi exposades.

\section{La cultura i l'educació com a eines de resistència de les persones}

En aquest bloc temàtic vam analitzar el relat de vida de l'Antoni en relació amb els camins de resistència que la cultura i l'educació han establert en la seva vida. Vam dividir el bloc en tres categories d'anàlisi: Experiència del no-res i disgregació de l'ésser, Resistència a la reproducció i Resistència íntima.

\section{Experiència del no-res i disgregació de l'ésser}

El relat de vida de l'Antoni està impregnat de l'experiència del no-res descrita per Esquirol (2015). És essencial contextualitzar les seves arrels per tal de comprendre aquesta relació. L'Antoni va néixer el 1962 a Gavà (Baix Llobregat). La seva mare era d'Extremadura i el seu pare d'Andalusia, es van conèixer a Madrid, es van casar a València i van venir a Catalunya a l'inici dels anys seixanta atrets per la possibilitat de trobar feina. Aquí van tenir quatre criatures. L'Antoni és el primogènit. Ell diu que les condicions de vida de la seva família eren molt humils, que vivien en estat de misèria i acostumaven a passar fam. El seu pare treballava a una empresa construint bigues i era assidu dels bars, mentre que la seva mare es feia càrrec de la casa sentint-se molt sola. El 1968, ella va tenir el seu primer episodi agressiu i va ser diagnosticada d'esquizofrènia. De tant en tant l'internaven a un hospital psiquiàtric, on estava un temps d'entre una setmana a un mes. Per això, quan el 1970 va néixer el tercer fill de la família, es va activar un sistema d'assistència social perquè el seu pare no hagués de fer-se càrrec de tres fills. L'Antoni va ser enviat, llavors, a un 
internat d'Auxilio Social de Barcelona, el qual era una institució franquista que adoctrinava en el nacionalcatolicisme a través de la violència, la por i la disciplina paramilitar. Ell afirma que va ser una experiència traumàtica que va marcar la seva vida perquè li van destrossar l'autoestima. El 1977, poc temps després de la mort de Franco, esdevinguda el 20 de novembre de 1975, es va tancar l'internat i ell va anar a estudiar a un institut a Saragossa: en aquesta ciutat va descobrir la llibertat. Així i tot, va suspendre algunes assignatures i, conscient que no les aprovaria el curs escolar següent, el juny de 1978 va tornar a Gavà per treballar i estudiar electricitat. A casa es va trobar amb una família desestructurada que contrastava amb l'ambient d'alegria que havia viscut a Saragossa. EI 1979, la seva mare va morir d'un càncer de mama. Ell tenia disset anys i, com el seu pare mai estava present, va haver de fer-se càrrec de la casa. Desmotivat i apàtic, el 1980 va abandonar els estudis.

L'Antoni expressa que al llarg d'aquestes vivències d'infància i adolescència va anar generant un profund buit i una asfixiant angoixa, no creia en ell i era incapaç d'expressar les seves emocions. Descobrim en ell a un nen tendre abocat a l'abisme de la misèria, la violència, la pèrdua i l'absència. En les seves paraules: «si un día me hubiese caído un rayo y me hubiese fundido, me hubiese dado igual y hasta aquí hemos llegado: se acabó». La seva experiència coincideix, doncs, amb l'experiència del no-res i la disgregació de l'ésser definida per Josep Maria Esquirol (2015) en què l'ésser humà es va submergint en el nores que porta dins i que s'intensifica en determinades circumstàncies que actuen com a forces disgregants. Aquestes vivències han establert un sòl àrid sobre el qual, malgrat tot, la cultura i l'educació han fet florir senders de resistència.

\section{Resistència a la reproducció}

Tal com hem introduït en la categoria d'anàlisi anterior, un dels processos que van actuar com una força disgregant de l'ésser en la vida de l'Antoni va ser el seu pas per l'internat d'Auxilio Social. És enriquidor que aprofundim en aquesta qüestió per tal d'analitzar la relació entre reproducció i resistència que en ella s'articula. Al llarg d'aquest període que va durar set anys, I'Antoni va ser oprimit pels mecanismes franquistes de reproducció social i cultural: les classes es basaven en «la letra con sangre entra», cada matí cantaven el Cara al sol, cada tarda passaven el rosari i els divendres feien missa. Ell destaca que els alumnes vivien en un estat d'angoixa permanent a causa de la violència constant que rebien per part del personal docent. Els cops i els insults eren el pa de cada dia i els infants també els feien servir per a sobreviure en aquell entorn tan hostil. Aquesta vivència del feixisme a l'internat exemplifica el plantejament de les teories de la reproducció i la resistència que les escoles són instruments de reproducció social i cultural (Giroux, 1985). Ara bé, aquestes teories també afirmen que aquesta reproducció es troba amb elements de resistència (Giroux, 1985). Aquest és el cas de l'Antoni que, estant a l'internat, va decidir que mai seguiria el joc de la violència i que volia convertir-se en una «enciclopedia con patas». Per exemplificar aquesta decisió ens explica que un company li va pegar mentre l'obligava a dir insults i, així i tot, ell es va negar rotundament. La seva manera de resistir, tal com defensa Esquirol (2015), no s'ha de confondre amb la protesta cridanera, sinó que era discreta. Es pot expressar amb les paraules de Giroux (1985):

Algunos estudiantes minimizan su participación en las prácticas de rutina de la escuela mientras que al mismo tiempo muestran una aparente conformidad con la ideología de la escuela y optan por modos de resistencia que son silenciosamente subversivos en el sentido más inmediato, pero que tienen el potencial para ser políticamente progresistas a largo plazo. (p. 46) 
En consonància amb aquesta idea, I'Antoni diu que va intentar passar desapercebut per sobreviure a l'internat, mentre que dins seu s'anava coent un desig de cultura i d'educació: I'horitzó d'esdevenir una «enciclopedia con patas» el feia resistir a l'opressió viscuda.

\section{Resistència íntima}

El desig de cultura i d'educació que va néixer en l'Antoni a l'internat l'ha acompanyat al llarg de la seva vida com una manera de resistir a les circumstàncies que actuen com a forces disgregants del seu ésser. Una altra d'aquestes és la seva situació laboral com a operari en una fàbrica d'injecció de cautxú, en la qual treballa des de 1999. La feina a la fàbrica és molt sacrificada físicament i l'ambient és força groller i agressiu. L'Antoni diu que els seus valors xoquen amb els dels seus companys i que ha hagut d'adaptar-se a la seva forma de relacionar-se per no tenir gaires conflictes. També expressa que ha conegut les seves històries i ha vist que les seves trajectòries vitals coincideixen en el fet de no haver tingut gaire accés a l'educació: són homes que han migrat des d'altres països per treballar des que van acabar els estudis bàsics o que han crescut en barris molt humils on les institucions educatives brillaven per la seva absència. En entendre els seus orígens compartits i les seves circumstàncies personals, ha après a establir punts de trobada amb ells. Així i tot, la seva feina no li satisfà gens intel-lectualment. En reacció a aquest fet, I'Antoni va participar en un club de lectura entre el 2006 i el 2014. A la biblioteca municipal s'hi trobaven mensualment persones estudiants, treballadores, aturades i jubilades de contextos molt diferents per compartir entorn de la literatura. L'Antoni recorda que un escriptor els hi va dir que seguissin així perquè eren les catacumbes de la cultura. En aquesta clandestinitat d'un espai fora de la seva quotidianitat, diu que tothom coincidia en el fet que el club de lectura era una bombolla on respiraven l'oxigen necessari per enfrontar-se a la rutina. Aquest va esdevenir, doncs, un espai de recolliment on aixecar fortalesa davant dels processos de desintegració que cal afrontar en el dia a dia o, en altres paraules, un espai de resistència íntima (Esquirol, 2015). Tot i que l'abril de 2014 l'Antoni va deixar d'anar al club perquè li costava compaginar la feina amb la lectura, la seva flama es manté viva. En les seves paraules es fa evident que la cultura i l'educació han mantingut un caràcter de resistència íntima en la seva vida:

El club de lectura era, y la cultura en general es, un espacio de resistencia intelectual. Desde allí puedo enfrentarme al mundo de hoy, a lo cotidiano, a la rutina. Creo que sin cultura no sería yo, no tendría fuerza. [...] En la cultura encontré un refugio y a través de ella busco comprender el mundo y a mí mismo, desarrollar una ética, tener criterios para actuar, tejer empatías y, ¡cómo no!, apreciar la belleza. [...] Como afortunadamente en el mundo en que vivimos hay mucha cultura, estoy contento, y este disfrute me permite sobrellevar el trabajo.

\section{La cultura i l'educació com a eines d'alliberament de les persones}

En aquest bloc temàtic vam analitzar el relat de vida de l'Antoni en relació amb els camins d'alliberament que la cultura i l'educació han establert en la seva vida. Vam dividir el bloc en dues categories d'anàlisi: Formació com a ser més i Trobada amb l'altre.

\section{Formació com a ser més}

Quan el 1977 es va tancar l'internat d'Auxilio Social, I'Antoni va continuar els seus estudis en un institut de Saragossa i va viure en una residència d'estudiants de la ciutat. Espanya vivia un moment de canvi perquè feia poc que havia mort Franco a la tardor de 1975 i s'albirava una incipient democràcia que omplia els carrers de flaire d'esperança. L'Antoni 
va viure un procés anàleg: vingut de la foscor opressiva de l'internat franquista, a Saragossa es va sentir en un nou món on podia decidir. Durant aquest temps va gaudir d'estudiar, va participar de la vida de la ciutat i va descobrir gran quantitat d'escriptors, músics i artistes que el van apassionar. El contrast entre l'internat i la nova ciutat va marcar un punt d'inflexió vital perquè va obrir-se al saber, la solidaritat i l'inconformisme. Quan va tornar a casa el 1978 va retrobar-se amb el seu buit. Per això, entre el 1983 i el 1986 va fer teatre amb el propòsit de formar-se per connectar amb si mateix. Aquesta intenció està en consonància amb el plantejament que formar-nos és transformar-nos constantment sent portats progressivament a la nostra forma singular i pròpia (Larrosa, 2017). Així va ser, ja que expressa que en el teatre va revisitar les seves emocions de manera orgànica i des de llavors se sent un ésser creatiu amb capacitat per transmetre-les. Va deixar-ho el 1986 perquè va entendre que no podria guanyar-se la vida com a actor i perquè desitjava estudiar Història a la universitat. En aquell moment va començar a anar a classes a una acadèmia per preparar-se per l'examen d'accés a la universitat per majors de vint-i-cinc anys. Aquell infant que desitjava ser una «enciclopedia con patas» va trobar el seu paradís durant aquell temps perquè va sentir com el coneixement el feia més Iliure. En l'expressió d'aquest fet l'Antoni coincideix amb Larrosa (2017) quan vincula la formació amb l'alliberament. Malgrat tot, el 1987 va suspendre l'examen perquè encara no tenia el convenciment suficient per actuar amb decisió sota pressió i va abandonar els estudis. Així i tot, ha seguit vinculat a processos formatius a través del cinema, la literatura i el teatre. Un exemple és el seu ja mencionat pas pel club de lectura, període durant el qual va atendre dos cursos d'escriptura que van ser el punt de partida de la seva passió per escriure relats.

L'Antoni diu que gràcies a totes aquestes experiències formatives s'ha sentit més humà perquè s'ha aproximat a si mateix en aprendre a qüestionar(-se), a crear i a entendre el món. Podem afirmar que van ser experiències alliberadores si recordem que l'alliberament és el moviment de les persones de cerca constant de ser més, és a dir, d'humanitzar-nos i transcendir-nos (Freire, 1979) en el marc d'un viatge obert en què canviem constantment (Larrosa, 2017). L'Antoni que va fer l'examen d'accés s'havia transformat més enllà de les càrregues del passat per mirar el món amb els ulls renovats. Són, per tant, vivències del vincle entre la cultura, l'educació i l'alliberament, el qual afirma que ha tingut molt present en l'educació de la seva filla volent ensenyar-li a gaudir del món, de la cultura i de la bellesa per tal de connectar amb la seva humanitat.

\section{Trobada amb l'altre}

Totes aquestes experiències formatives alliberadores tenen un tret en comú: s'han donat en la trobada amb les altres persones. Lepecki (2018) afirma que en la trobada amb l'altre s'enllacen «la poètica, la política, la performance, la vida, l'art i l'ètica com a camps que ressonen entre si per saber viure una vida que val la pena de ser viscuda» (p. 25). Un exemple d'aquesta trobada amb l'altre és que la seva estada a la residència d'estudiants de Saragossa va suposar per l'Antoni entendre's com un subjecte actiu amb veu i capacitat de decisió, ja que els residents feien assemblees, organitzaven la vida comunitària mitjançant comitès i convocaven vagues contra la pressió escolar. Després del silenci que se li havia exigit a l'internat, participar va ser alliberador per ell perquè significava donarse valor com a part d'un col-lectiu. Aquesta experiència il.lustra la idea de Freire (1979) que l'alliberament es realitza en la comunió i la solidaritat de les persones. En aquest punt és necessari que recuperem la idea que alliberar-se és humanitzar-se i que ens humanitzem quan ens formem. Tenint en compte que en un món emparaulat només és possible aprendre a través del diàleg (Vilanou, 2002), és versemblant assumir que l'alliberament 
es dóna en ell. Volem exemplificar aquesta qüestió amb dos diàlegs que van nodrir profundament a l'Antoni. El primer és el que va tenir en les diverses sessions del club de lectura perquè, com cada persona aportava la seva mirada singular en el debat entorn dels llibres, cada sessió s'obrien múltiples perspectives des d'on qüestionar-se i repensar-se. El segon és la xerrada i posterior col-loqui que va donar a l'institut de la seva filla durant el curs 2015-2016 per parlar sobre la seva experiència a l'internat d'Auxilio Social perquè compartir quelcom que sempre havia reposat al pou de l'ànima va tenir un efecte catàrtic en ell alhora que es va sentir empoderat pel fet de desenvolupar una tasca de sensibilització contra el feixisme. Aquests són només alguns exemples de moments de trobada amb l'altre narrats per l'Antoni, ja que el seu relat està atapeït d'ells. L'èmfasi de la qüestió es troba en el fet que ell expressa que aquests van ser espais d'intercanvi per sentir-se més humà i, per tant, per formar-se i alliberar-se.

\section{La cultura i l'educació com a eines d'alliberament i de resistència de les persones}

En aquest bloc temàtic vam analitzar els elements de la cultura i l'educació que han possibilitat que aquestes creïn tant camins de resistència com d'alliberament en la vida de l'Antoni. Vam dividir el bloc en tres categories d'anàlisi: Comprensió, reflexió i memòria; Transformació, acció i imaginació i Reflexió crítica.

\section{Comprensió, reflexió i memòria}

Per introduir aquesta categoria d'anàlisi és necessari tornar sobre les idees que els éssers humans som animals culturals oberts al món (Sánchez, 1996), que la cultura és un conjunt d'esquemes que donen perfils a un món que es presenta amorf i desordenat abans de la seva mediació (Larrosa, 2017) i que l'educació és el procés en què les persones ens apropiem d'aquesta. Per tant, necessitem la cultura i l'educació per comprendre el món. En relació amb aquest fet, l'Antoni explica que un dia va anar amb un dels seus germans al monestir de Santes Creus i aquest no podia entendre que ell gaudís tant de veure la construcció. El seu germà només mirava l'espai mentre ell sentia una profunda joia en entendre el nom, l'origen, la raó de ser i la història d'aquest. Aquest desig de coneixement ja s'intuïa en la seva decisió d'infància d'esdevenir una «enciclopedia con patas», però va despertar-se amb força durant el seu pas per l'acadèmia en què es va preparar per a l'examen d'accés a la universitat perquè, gràcies a dos professors, va gaudir intensament d'aprendre Història i Història de l'art. En l'anècdota de l'Antoni també trobem que vincula la comprensió amb la memòria, qüestió que encaixa amb el fet que les persones som éssers històrics (Freire, 1979; Sánchez, 1996; Larrosa, 2017) i, per tant, tenim memòria com una manera de comprendre el present. La reflexió és un altre element al qual es troba unida la comprensió perquè les persones som éssers de praxi (Freire, 1979) i, en aquest marc, reflexionar és un procés necessari per comprendre. L'Antoni diu que llegir novel.les l'inspira a reflexionar perquè, en tenir accés a l'univers íntim dels personatges, emfasitza amb ells i descobreix múltiples perspectives sobre els problemes socials que retraten. Quant a la comprensió de si mateix, afirma que els exercicis d'introspecció que va fer en teatre li van permetre ser conscient orgànicament del dolor i desànim que portava a la seva motxilla vital $i$, en aquest intens sentiment, va adonar-se que necessitava engegar canvis. En conjunt, expressa que la cultura i l'educació han sigut senders de resistència i $d^{\prime}$ alliberament per ell perquè li han permès reflexionar i tenir memòria per comprendre el món i a si mateix. Resumint-ho amb les seves paraules: «Entiendo que la cultura nos puede ayudar a ser más libres porque el conocimiento nos ayuda a entender el mundo y a nosotros mismos». 


\section{Transformació, acció i imaginació}

La comprensió es troba profundament unida a la transformació, ja que les persones transformem la realitat i alhora aquesta ens condiciona (Freire, 1979). És per aquest motiu que Freire (1979) defineix el diàleg educatiu com la trobada de les persones per pronunciar el món, com una exigència existencial per comprendre'l i com un acte creador per transformar-lo. L'Antoni també vincula la cultura, la comprensió i la transformació quan afirma que «tener cultura es esencial para sentir de dónde venimos, para nutrirnos como seres humanos, para no olvidar, para comprender el presente y para crear un futuro mejor». I afegeix l'educació a aquest vincle en explicar que el club de lectura va ser una clariana d'imaginació que s'obria entre l'espessor de la rutina i l'impulsava a transformar la seva quotidianitat. Identifiquem, doncs, que uneix la transformació amb la imaginació. De nou, aquesta qüestió encaixa amb el fet que les persones som éssers històrics (Freire, 1979; Larrosa, 2017; Sánchez, 1996) i tenim imaginació com una manera de visualitzar noves realitats. Tot i que en la imaginació ens adonem que un altre món és possible, cal actuar per crear els canvis que volem veure. L'acció és, per tant, un altre element al qual es troba unida la transformació perquè les persones som éssers de praxi (Freire, 1979) i, en aquest marc, actuar és un procés necessari per transformar. La capacitat per actuar de manera coherent amb si mateix és, precisament, l'aprenentatge més preuat que l'Antoni guarda del teatre: durant el seu pas pels escenaris va desenvolupar el seu autoconeixement, expressivitat, confiança, observació i creativitat per poder tirar endavant els canvis que volia en la seva vida. En conjunt, expressa que la cultura i l'educació han sigut vies de resistència i d'alliberament per ell perquè li han permès actuar i imaginar per transformar el món i a si mateix. Aquest bagatge vital es reflecteix quan diu que l'essència de l'educació de la seva filla s'ha basat en el fet que no es conformi amb el que és políticament correcte ni amb el que s'espera d'ella, sinó que s'expressi tal com és, prengui decisions que vagin amb ella, es formi per poder actuar sobre el món amb criteri i s'arrisqui a ser els canvis que desitja.

\section{Reflexió crítica}

Anteriorment hem desenvolupat que, gràcies a aquest potencial per mobilitzar processos comprensius i transformadors, la cultura i l'educació tenen la possibilitat de ser senders de resistència i d'alliberament de les persones. Volem emfatitzar el caràcter de possibilitat, ja que perquè realment ho siguin el seu sentit s'ha d'orientar en aquesta direcció (hooks, 1994). Les següents paraules de l'Antoni ens revelen l'element que cal promoure per fer-ho:

\section{La cultura nos puede ayudar a desarrollar el sentido crítico, ya que nos da referencias para actuar con cri- terio. El peligro de la cultura también es que hay élites culturales que dejan de tener sentido crítico para creerse que son el centro del mundo y que éste tiene que ser como ellos digan. [...] El sentido crítico nos ayuda a estar despiertos y atentos a qué podemos mejorar para crear una sociedad menos autocompla- ciente.}

Parla, doncs, de la reflexió crítica. Al llarg del seu camí formatiu, I'Antoni ha anat desenvolupant una mirada crítica que qüestiona els poders i les estructures que es troben a l'arrel de les misèries, els buits i les pors que ha viscut. Contundent contra el feixisme i les desigualtats socials, en el seu relat vital es poden llegir diverses anècdotes de defensa dels drets humans, de la llibertat i de la democràcia. Presentem una del club de lectura que, malgrat la seva extensió, il-lustra clarament el vincle entre la cultura, l'educació i la reflexió crítica: 
Leímos un libro que se llama Muerte en la Fenice, que es una historia policíaca en Venecia sobre un director de orquesta que muere en la Fenice. Dentro de la historia, hay una soprano que, cuando llegó el fascismo a Italia, podría haber seguido trabajando en poner su arte al servicio de ellos. Pero ella decide que no va a participar del movimiento fascista y las autoridades italianas la arrinconan, la condenan al ostracismo y al olvido. [...] Entonces, en la sesión del club de lectura, una chica dijo que la soprano era poco inteligente, puesto que si se hubiese puesto al servicio de los nazis no hubiera perdido su posición de diva. A mí con ese comentario me entró una cosa por dentro... Y delante de todos y muy seriamente le dije: «Yo considero que de inteligencia no le falta nada, porque con la coherencia y el valor que tuvo de sacrificarlo todo en aras de sus valores... Sí, le costó su carrera, pero tenía una cosa: que seguramente todas las noches de su vida pudo dormir con la conciencia muy tranquila».

Conscient del valor de la reflexió crítica en la seva vida, I'Antoni coincideix amb Freire (1990) en què la cultura i l'educació han de fomentar la reflexió crítica per tal de ser eines de resistència i d'alliberament de les persones.

\section{Conclusions}

Recuperem les sensacions que el lector o lectora ha evocat en pensar en el seu llibre preferit, la cançó gravada en els seus records i el mestre o mestra que li va deixar petjada. Aquestes han sigut el punt de partida de la recerca que hem presentat perquè són vivències compartides en què les persones sentim que la cultura i l'educació ens connecten amb la nostra humanitat, ens fan aixecar fortalesa i ens porten a transcendir-nos. En un intent de comprendre aquestes sensacions, ens hem proposat l'objectiu d'explorar la cultura i l'educació com a camins de resistència i d'alliberament fent una anàlisi hermenèutica del relat de vida d'una persona. Després d'endinsar-nos en el marc teòric del tema, en el valor pedagògic de la tècnica dels relats de vida i en l'estudi del cas de l'Antoni, farem una síntesi de les conclusions que hem extret.

La primera és que la cultura i l'educació són eines de resistència i d'alliberament de les persones en la mesura que fomenten la reflexió crítica, la qual suposa la inserció crítica de les consciències de les persones en la realitat. Per arribar a aquesta conclusió hem indagat en els conceptes pedagògics de cultura, d'educació, de resistència i d'alliberament, els hem definit i hem mostrat els vincles que existeixen entre ells. En aquest procés ens hem adonat que la cultura i l'educació no són pas camins establerts, sinó que es creen en el nostre caminar perquè en ells ens fem, desfem i refem constantment (Larrosa, 2017). En aquest canvi constant, la cultura i l'educació ens permeten comprendre('ns) i transformar(-nos) (Freire, 1979). Malgrat això, poden ser tant el subjecte com l'objecte de la resistència (Giroux, 1985) i tenen la possibilitat tant d'oprimir-nos com d'alliberar-nos (Freire, 1979), ja que el diàleg dels éssers humans amb el món pot tant humanitzar-nos com deshumanitzar-nos a causa de la nostra naturalesa problemàtica (Freire, 1990). Per orientar l'acció educativa en el sentit de la resistència i l'alliberament necessitem, doncs, promoure la reflexió crítica perquè aquesta ens convida a qüestionar, a imaginar nous horitzons individuals i comunitaris i a actuar amb criteri per generar canvis (Freire, 1990).

La segona conclusió és que la cultura i l'educació han sigut camins de resistència i d'alliberament en la vida de l'Antoni. Aquesta es relaciona amb la conclusió anterior perquè analitzant el seu relat de vida ens hem adonat que, tot $\mathrm{i}$ la duresa de les seves experiències d'infància i adolescència, la cultura i l'educació han sigut el seu refugi i obertura al món i, en aquest procés, la reflexió crítica ha jugat un paper essencial. Ell va néixer en el si d'una família molt humil que ha hagut de viure desventures com la misèria, la mort de la mare i l'absència del pare. Si unim la desestructuració familiar amb el pas de l'Antoni per l'internat d'Auxilio Social, entendrem perquè diu que va anar generant un profund 
buit i una asfixiant angoixa, no creia en ell i no tenia autoestima. Aquestes experiències han establert un sòl àrid en què, malgrat tot, la cultura i l'educació han sigut les llavors que han fet florir de nou la vida. Gràcies a elles ha après a gaudir del coneixement, de la creació, de la bellesa i de la solidaritat i ara, amb cinquanta-vuit anys, mira enrere en el temps com un home culte i crític.

El fet de fer ús de la tècnica dels relats de vida ens ha conduït a una tercera conclusió: aquesta tècnica -i la investigació biogràfica-narrativa en general- és valuosa per la investigació educativa perquè ens permet diversificar els discursos pedagògics i, així, tenir una comprensió complexa de la realitat educativa. Com bé hem exposat anteriorment, les potencialitats d'aquesta tècnica en l'àmbit de la pedagogia són que pot atendre a la subjectivitat de les persones (Bolívar, 2002), democratitzar els discursos acadèmics (Bolívar, 2002; Ferrando, 2018) i empoderar els subjectes (Rueda, 2004). Al llarg de la recerca que hem presentat, hem pogut experimentar aquestes potencialitats per adonar-nos que la seva força resideix en la capacitat de desvetllar l'ocult per fer visibles les realitats sentides que sovint resten sense anomenar. Aquest fet suposa un canvi de mirada que posa sobre la taula la quotidianitat de la varietat de veus que habiten els contextos educatius per tal de generar transformacions que donin resposta als desitjos, les necessitats i els problemes reals de les persones.

Aquestes conclusions ens obren un nou interrogant per seguir investigant: com podem promoure la reflexió crítica des dels diversos contextos educatius? En aquesta recerca hem buscat comprendre la cultura i l'educació com a camins de resistència i d'alliberament de les persones. Aquesta comprensió ha de permetre que els professionals de l'educació tinguem criteri per desenvolupar discursos i pràctiques educatives emancipatòries que, en coherència amb el pensament pedagògic actual, estiguin compromeses amb el desenvolupament integral de les persones, el respecte a la diversitat, la llibertat, l'equitat i la democràcia. En altres paraules, aquesta comprensió ens ha de permetre fer el salt a la transformació. Està en les nostres mans impulsar processos de transformació educativa que portin les persones a mantenir viva la flama de la resistència i a ser més. Per això, convidem el lector o lectora a preguntar-se com fomentar la reflexió crítica des de la seva acció educativa i, per tant, a seguir reflexionant amb l'horitzó posat en construir un món més equitatiu on les desigualtats es desfacin i totes les persones gaudim de la nostra diversitat.

\section{Referències}

Ascanio, C. (1995) «Biografía etnográfica». A A. Aguirre (Coord.), Etnografía: metodología cualitativa en la investigación sociocultural. Barcelona, Marcombo, p. 209-220.

Bertaux, D. (2005) Los relatos de vida: perspectiva etnosociológica. Barcelona, Bellaterra.

Bolívar, A. (2002) "“De nobis ipsis silemus?": epistemología de la investigación biográfico-narrativa en educación». Revista Electrónica de Investigación Educativa, 4 (1). Recuperat el 2 de maig de 2020 de: http://www.scielo.org.mx/pdf/redie/ v4n1/v4n1a3.pdf

Denzin, N. K. i Lincoln, Y. S. (1994) «Introduction: entering the Field of Qualitative Research». A N. K. Denzin i Y. S. Lincoln (Eds.), Handbook of Qualitative Research. California, Sage, p. 1-17.

Esquirol, J. M. (2015) La resistència íntima: assaig d'una filosofia de la proximitat. Barcelona, Quaderns Crema. 
Ferrando, E. (2018) «Potencialitats educatives de les fonts orals». Senderi. Recuperat el 9 de març de 2020 de: http://www.senderi.org/cat/articles/139/potencialitatseducatives-de-les-fonts-orals

Freire, P. (1979) Pedagogía del oprimido. Madrid, Siglo XXI de España.

Freire, P. (1990) «Acción cultural y concienciación». A P. Freire, La naturaleza política de la educación: cultura, poder y liberación. Barcelona, Ministerio de Educación y Ciencia i Paidós Ibérica, p. 85-111.

Giroux, H. (1985) «Teorías de la reproducción y la resistencia en la nueva sociología de la educación: un análisis crítico». Cuadernos políticos, 44, p. 36-65. Recuperat I'1 de desembre de 2019 de: http://www.cuadernospoliticos.unam.mx/cuadernos/ contenido/CP.44/cp.44.6.\%20HenryAGiroux.pdf

hooks, b. (1994) Teaching to Transgress. Londres, Routledge.

Larrosa, J. (2017) Pedagogía profana: estudios sobre subjetividad, lenguaje y educación. Buenos Aires, Miño y Dávila.

Lepecki, A. (2018) Idiorítmia, o en l'esdeveniment d'una trobada. Barcelona, MACBA.

Martín, A. V. (1995) «Fundamentación teórica y uso de las historias y relatos de vida como técnicas de investigación en pedagogía social». Aula, 7, p. 41-60. Recuperat el 25 de novembre de 2019 de: https://revistas.usal.es/index.php/0214-3402/article/ view/3375

Rueda, R. (2004) «El mètode biogràfic: la tornada al subjecte i a la interacció com a centre del procés investigador». Temps d'Educació, 28, p. 55-84. Recuperat el 26 de juliol de 2020 de: https://www.raco.cat/index.php/TempsEducacio/article/view/126399

Saint-Exupéry, A. (2003) El petit príncep. Barcelona, Salamandra.

Saltalamacchia, H. R. (1987) «Historia de vida y movimientos sociales: el problema de "la representatividad" (apuntes para la reflexión)». Revista Mexicana de Sociología, 49 (1), 255-277. Recuperat el 12 de març de 2020 de: https://www.academia.edu/12819500/ Historia_de_vida_y_movimientos_sociales_el_problema_de_la_representatividad

Sánchez, M. (1996) «El hombre como "ser-proyecto", objeto formal de la antropología filosófica». Anales Del Seminario De Historia De La Filosofía, Extra 1, p. 485-495. Recuperat el 26 de gener de 2020 de: https://revistas.ucm.es/index.php/ASHF/ article/view/ASHF9696220485A

Susinos, T. i Parrilla, A. (2008) «Dar la voz en la investigación inclusiva: debates sobre inclusión y exclusión desde un enfoque biográfico-narrativo». REICE, 6 (2), p. 157-171. Recuperat el 2 de maig de 2020 de: https://revistas.uam.es/index.php/reice/ article/view/5447

Vilanou, C. (2002) «Formación, cultura y hermenéutica: de Hegel a Gadamer». Revista de Educación, 328, p. 205-223. Recuperat el 4 de gener de 2020 de: https://pdfs.semanticscholar.org/a84a/19dc9440154af6120c38922aeea822229c135.p df 


\section{La cultura y la educación como caminos de resistencia y de liberación: un estudio de caso}

Resumen: En este artículo presentamos una investigación cuyo objetivo es explorar la cultura y la educación como herramientas de resistencia y de liberación de las personas mediante la técnica de los relatos de vida. A lo largo del texto desarrollamos una exploración teórica del tema, una reflexión sobre el valor pedagógico de los relatos de vida y un estudio de caso en que hacemos un análisis hermenéutico del relato de vida de una persona. Los resultados obtenidos proponen que la cultura y la educación son caminos de resistencia y de liberación de las personas en la medida que fomentan la reflexión crítica y nos abren la puerta a seguir preguntándonos como desarrollar procesos de transformación educativa que den respuesta a las problemáticas sociales contemporáneas.

Palabras clave: resistencia, liberación, reflexión crítica, transformación educativa, investigación biográfica-narrativa, relatos de vida.

\section{La culture et l'éducation en tant que moyens de résistance et de libéra- tion: une étude de cas}

Résumé: Dans cet article, nous présentons une recherche qui a pour objectif d'explorer la culture et l'éducation en tant qu'outils de résistance et de libération des personnes à travers la technique des récits de vie. Tout au long du texte, nous développons une analyse théorique de la question, une réflexion sur la valeur pédagogique des récits de vie et une étude de cas dans laquelle nous réalisons une analyse herméneutique du récit de vie d'une personne. D'après les résultats obtenus, la culture et l'éducation apparaissent comme des moyens de résistance et de libération des personnes, dans la mesure où elles encouragent la réflexion critique et qu'elles nous ouvrent la voie pour continuer à nous interroger sur la façon de développer des processus de transformation éducative permettant de faire face aux problématiques sociales contemporaines.

Mots-clés: Résistance, libération, réflexion critique, transformation éducative, recherche biographique-narrative, récits de vie

\section{Culture and education as paths of resistance and liberation: a case study}

Abstract: In this article we use the life stories technique to study culture and education as personal tools of resistance and liberation. Throughout the text, we carry out a theoretical exploration of the topic and reflect on the pedagogic value of life stories. We make a hermeneutic analysis of a person's life story. The results suggest that culture and education are paths of resistance and liberation for people if they promote critical reflection. The findings encourage us to continue asking ourselves about how to deploy educational transformation processes able to respond to contemporary social problems.

Key words: resistance, liberation, critical reflection, educational transformation, biographical-narrative research, life stories. 